\title{
Local conditions $v s$ regional context: variation in composition of bird communities along the Middle Paraná River, an extensive river-floodplain system of South America
}

\author{
R. E. Lorenzón ${ }^{1,4}$, A. H. Beltzer ${ }^{1}$, P. M. Peltzer ${ }^{2}$, A. L. Ronchi-Virgolini³ ${ }^{3}$ M. Tittarelli1 \\ and P. Olguin 1
}

\author{
Instituto Nacional de Limnología (INALI-CONICET-UNL), Ciudad Universitaria (3000), Santa Fe, Argentina \\ ${ }^{2}$ Facultad de Bioquímica y Ciencias Biológicas (ESS-FBCB-CONICET), Ciudad Universitaria (3000), Santa Fe, \\ Argentina \\ ${ }^{3}$ Universidad Autónoma de Entre Ríos (UADER), Corrientes y Andrés Pasos (3100), Paraná, Argentina \\ ${ }^{4}$ Corresponding author: E-mail: roylorenzon@gmail.com
}

Keywords: Beta diversity, Nestedness, Riparian corridor, Spatial structure, Species turnover, Variation-partitioning, Wetlands.

\begin{abstract}
We studied spatial changes in species composition (i.e., beta diversity) of local assemblages of birds along $450 \mathrm{~km}$ of the Middle Paraná River, an extensive fluvial system of South America. Point counts were used to survey birds at 60 plots located in shrub swamps and marshes of the floodplain within four sites (15 plots per site). Two sites were surrounded by each of the two upland ecoregions. Beta diversity of bird assemblages was high and was more important than alpha diversity in shaping regional diversity (i.e., gamma diversity) of the fluvial system. Compositional changes were related to species turnover among plots, while nestedness dissimilarity was not important for shaping diversity patterns. Variation-partitioning analysis showed that local conditions (i.e., landscape composition within a radius of $200 \mathrm{~m}$ from the center of each plot) accounted for more spatial variation in assemblage composition than did location along the fluvial system. Adjacent upland ecoregions did not account for spatial changes in bird composition within the fluvial system. In conclusion, environmental heterogeneity created by flood pulses is an important factor for sustaining regional diversity of birds within the fluvial system through effects on beta diversity.
\end{abstract}

Nomenclature: Remsen et al. (2015) for birds.

Abbreviations: RDA-Redundancy Analysis ordination, PERMANOVA-Permutational Multivariate Analysis of Variance

\section{Introduction}

River-floodplain systems are among the most complex and biologically diverse ones which play an important role in maintaining biodiversity by providing an extraordinary array of habitats (Naiman et al. 2005, Miller et al. 2004). However, the high degree of degradation of many fluvial systems, combined with the need for appropriate management strategies (Tockner et al. 2010), has made it crucial to understand what factors create and maintain the high biodiversity of these systems.

Ecologists have spent considerable effort attempting to distinguish among different components of species diversity in order to properly analyze and understand spatial variation in diversity (Amori et al. 2010). Initially, Whittaker (1960) used the term "gamma diversity" to refer to the full diversity of a given area (e.g., regional diversity) and partitioned it into two components: alpha, the diversity of species at individual sites; and beta, a measure of variability in species composition from one site to another. Since this partition was proposed, further improvements have been suggested (e.g., Baselga 2010). In this context, it is important to consider these different components of diversity because they may influence regional diversity in different ways and because they may involve different management and conservation strategies (Baselga 2010).

Species composition of a local community reflects environmental traits of the site (i.e., local conditions) as well as characteristics of the region (i.e., regional factors) in which it is currently situated (Chase and Myers 2011). Many ecological studies that have focused only on local environmental features and processes have underestimated the contribution of regional-scale processes to beta diversity among local assemblages (Ricklefs 1987). In part this has been because most studies of local assemblages have been conducted at local scales and have not considered environmental gradients at a regional scale (Lessard et al. 2011).

When studying the causes of spatial variation in community composition, the spatial structure of ecological data may act as a synthetic variable for the underlying processes that 
have generated it (Borcard et al. 1992). At a regional extent, spatial structure of local communities (i.e., variation related to specific geographic location) can be considered a surrogate of regional influences such as climate and/or the regional species pool (Kilpatrick et al. 2006). Regional characteristics may help explain differences in species composition among local communities after controlling for local environmental conditions (Belmaker and Jetz 2012).

In extensive fluvial corridors, geographic position of local communities can reflect regional influences along both longitudinal and lateral dimensions. Regional influences can be related to environmental gradients along the fluvial system and/or longitudinal or lateral dispersal processes (i.e., dispersal of organisms along the corridor and from adjacent uplands; Demars and Harper 2005, Renöfält et al. 2005). Recent attention has focused on the degree to which upland habitats contribute organisms to riparian ecosystems (Renöfält et al. 2005) and it has been suggested that regional classifications (e.g., ecoregions) of surrounding uplands may drive diversity patterns of the adjacent riparian biota (Heino et al. 2002). Despite this, most studies on spatial changes of communities in river systems have focused on the effect of local environmental conditions regardless of whether or not those local conditions change along the regional extent of these river systems (Demars and Harper 2005). Thus, the relative influence of different groups of factors (i.e., local environmental conditions, spatial structure of environmental conditions, and regional processes independent of local environmental conditions, such as dispersal) on assemblage composition is still poorly understood because few studies have included these different factors simultaneously (White and Hurlbert 2010).

Most of the bird studies conducted in riparian landscapes have assessed the influence of local environmental conditions or dispersal processes on community composition, but without assessing the importance of these factors simultaneously. Thus, several studies have shown that composition of bird assemblages in fluvial corridors is related to local environmental conditions (e.g., Godinho et al. 2010, Henden et al. 2013), presumably because of the pronounced environmental heterogeneity of these systems (Naiman et al. 2005). Regionally, bird species are widely dispersed along riparian corridors (da Silva 1996, Nores et al. 2005) and from adjacent uplands (Sullivan et al. 2007, Perry et al. 2011). Thus, whereas bird assemblage composition can be strongly influenced by local environmental conditions (i.e., niche-based processes), the regional position along extensive fluvial systems could also be important because composition may reflect influences of dispersal processes that occur at a regional scale.

The Middle Paraná River represents an extensive floodplain-river system that forms a north-south riparian corridor of $\sim 600$ kilometers (Nestler et al. 2007, Iriondo et al. 2007). Along its route, the middle Paraná riparian corridor traverses a climatic gradient and two major upland ecoregions. Here, we 1) assessed the relative importance of alpha and beta diversity to shape the regional species pool of the system; 2) described spatial patterns in beta diversity (species turnover and nestedness dissimilarity) among local assemblages; 3) tested the relative importance of some local environmental conditions (i.e., landscape composition) and regional position (i.e.., geographic coordinates) with respect to spatial changes in composition of local assemblages along the regional extension of this riparian system; and 4) assessed if adjacent upland ecoregions can account for compositional changes of bird assemblages within the fluvial system. Because of the large regional extent of the river system, which traverses a climatic gradient and two different upland ecoregions, we predicted that the spatial position of bird assemblages along the riparian corridor would be more important than the local environmental conditions (i.e., landscape composition) in accounting for the beta diversity of the bird assemblages. More precisely, we predicted that beta diversity should reach its highest values when comparing bird assemblages between those parts of the river system that are surrounded by different upland ecoregions. This prediction is based on the observation that such upland systems can be good predictors of change in the species composition of riparian biota (Heino et al. 2002).

\section{Materials and methods}

\section{Study system}

Our study system includes the middle section of the Paraná River (Fig. 1). This corridor begins at the confluence of the Paraguay and Paraná rivers $\left(27^{\circ} 17^{\prime} \mathrm{S}-58^{\circ} 38^{\prime} \mathrm{W}\right)$, and extends $\sim 600 \mathrm{~km}$ to the beginning of the Paraná River Delta ( $32^{\circ} 04^{\prime} \mathrm{S}-60^{\circ} 38^{\prime} \mathrm{W}$; Nestler et al. 2007). This part of the river is included in the Paraná Flooded Savanna ecoregion (Olson et al. 2001), since it has a well-developed floodplain composed of streams and seasonally flooded islands. Islands show a topographic gradient from the highest sectors that are dominated by woods to lower areas dominated by shrubs, herbaceous plants and open water (Sabattini and Lallana 2007). The environments in which we conducted our studies included shrub swamps and marshes. These environments are dominated by shrubs and herbaceous plants that can tolerate hydric soils due to permanent (water bodies) or periodic (intermediate areas) presence of water, which varies with topographic height and the influence of the hydrological pulse (Sabattini and Lallana 2007). Water bodies and their edges are dominated by herbaceous plants (e.g., Panicum elephantipes, Sagittaria montevidensis) and shrubs (e.g., Solanum glaucophyllum, Sesbania virgata). Various floating plants (e.g., Eichhornia spp., Pistia stratiotes and Salvinia spp.) were present in more open water areas. Intermediate areas were dominated by Panicum prionitis. Scattered woody individuals of such species as Acacia caven, Sapium haematospermun and Albizia inundata were also present.

The climate is subtropical-humid in the northern parts, where average annual temperature is $21^{\circ} \mathrm{C}$ and annual rainfall is $1100 \mathrm{~mm}$ (Cáceres 1980), shifting to temperate-humid in the south (Iriondo et al. 2007), where mean annual temperatures are around $19^{\circ} \mathrm{C}$ and average annual rainfall is 900 mm (Rojas and Saluso 1987). Along its route, Middle Paraná River traverses mainly the Humid Chaco and Espinal ecoregions that differ in climate, soil type, flora and physiognomy 
of vegetation (Olson et al. 2001, Fig. 1). The Humid Chaco ecoregion is dominated by xerophytic semi-deciduous forests; palm groves, savannas and halophytic steppes also occur in this region (Cabrera 1994). The Espinal ecoregion is dominated by xerophytic forests that are similar to those in the Humid Chaco ecoregion but which are lower and without any Schinopsis species. The Espinal ecoregion is transitional between the Chaco and Humid Pampas ecoregions where grasslands begin to replace woody vegetation. Both the Humid Chaco and the Espinal ecoregions have been extensively modified for agriculture and livestock.

\section{Sampling design}

We sampled birds in four sites (A, B, C and D) located along $\sim 450 \mathrm{~km}$ of the Middle Paraná River (Fig. 1). Sites were located along the sides (relative to the course of Paraná River) of the floodplain. Sites A and B were in that part of the riparian corridor surrounded by the Humid Chaco ecoregion; sites $\mathrm{C}$ and $\mathrm{D}$ were surrounded by the Espinal ecoregion.

Within each site, we sampled 15 plots. Plot distribution was determined using the regular sampling method (Gregory et al. 2004). Plots were located along waterways to ensure accessibility under the different hydrological conditions of the river. Navigable waterways located predominantly in a northsouth direction were previously selected to represent the side of the floodplain within each site. The location of the first plot in each site was determined by the availability of boat ramps and navigable rivers as we required motorboats to move from plot to plot. However, bird counts were conducted on terra firme. The first plot was selected arbitrarily at the same latitude as that of boat ramps at each site on the bank of selected waterways for logistical considerations. From that first plot, we separated the remaining plots by 800 meters along the river in a predominantly north-south direction. When there was no accessible location at which to establish a plot (e.g., where stream banks were covered with dense riparian forests), we increased the distances between plots until suitable areas were encountered.

\section{Bird data collection}

The birds in each of the 60 plots were sampled by a multiple-visits fixed-radius point-count technique (i.e., one point count per plot; Ralph et al., 1993), which has been shown to be an effective method for sampling birds in riparian areas (Dobkin and Rich 1998). Each point was sampled approximately every 45 days during 2011-2013, for a total of 16 samples per point (i.e., two counts per season, four seasons per year, two years). All birds seen and heard within a radius of 100 meters from each point were recorded during $10 \mathrm{~min}$ (Gregory et al. 2004). We used a relatively large radius because counts were conducted in open areas with good visibility (Savard and Hooper 1995). We used range-finders for distance determinations. Probabilities of detecting species could vary among point counts, depending on habitat, time of day, and other factors (e.g., observer). To help reduce variation in detectability, bird counts began at sunrise and continued for 4 hours, a period of greater stability in terms of detecting birds (Robbins 1981). Further, we alternated (northwards versus southwards) the order in which points were sampled to reduce possible effects of time of day (Verner and Milne 1989). Also, we selected only shrub swamps and marshes, so visibility was good in all cases. Moreover, we repeated the surveys (16 visits per point), increasing the probability of detecting species present at a given point (presence was defined as the detection of the species in at least one of 16
Figure 1. Location of Middle Paraná River in the southern cone of South America showing four study sites (A, B, C, D), distribution of plots, and the two ecoregions through which this section of the river runs.

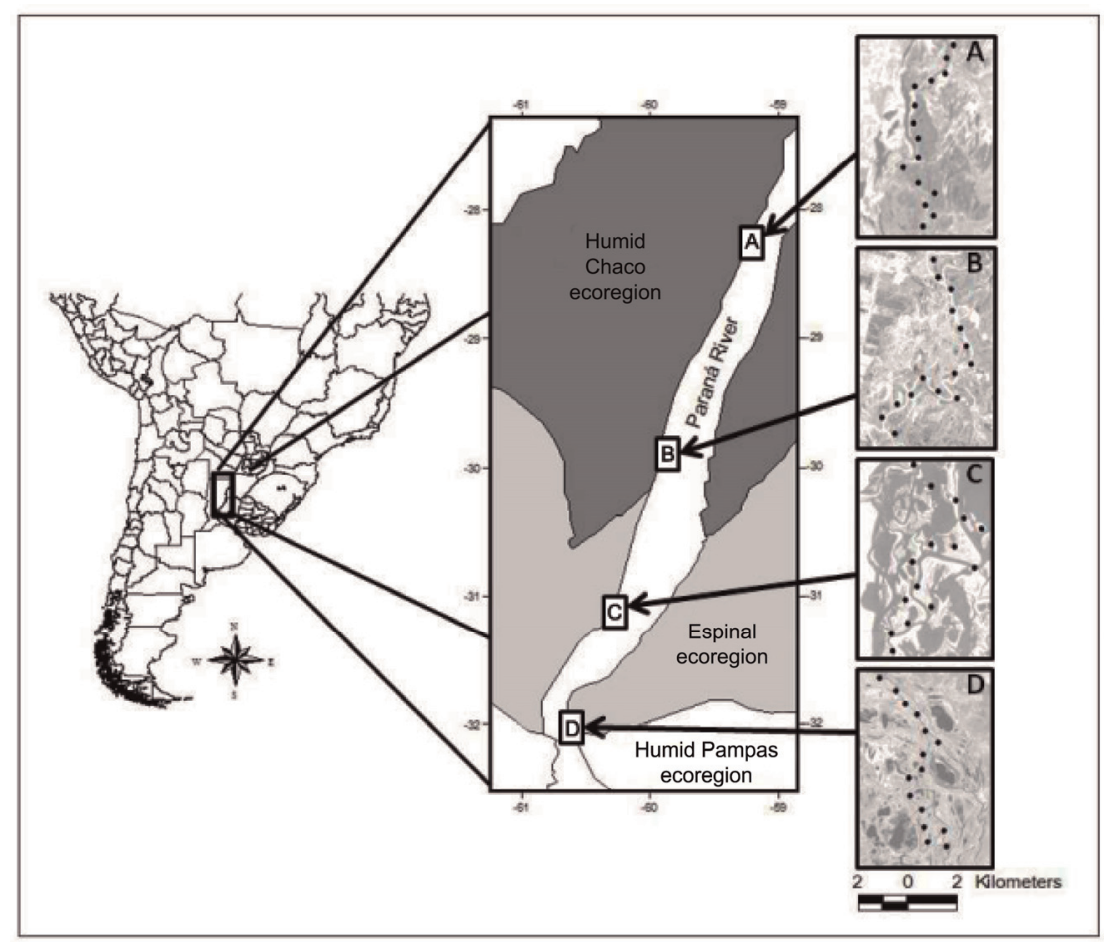


visits to each site, relative abundances were averaged among the 16 visits per point in data analysis, $\mathrm{Gu}$ and Swihart 2004). All ccounts were performed by the same observer who was familiar with the regional avifauna.

\section{Measures of local conditions}

Topographic relief within floodplains produces different patterns of connectivity that vary with river pulses and water depth, producing a shifting mosaic of environmentally diverse patches with distinct physiognomies (Ward et al. 1999). Consequently, we used primarily physiognomic criteria to classify these patches by vegetation type or other types of land cover when vegetation was absent. Land-cover types considered were: (1) open water, (2) floating macrophytes (e.g., Eichhornia spp., Pistia stratiotes and Salvinia spp., (3) emergent macrophytes (e.g., Panicum elephantipes, Sagittaria montevidensis), (4) shrublands, (5) grazed pastures, (6) beach, (7) grasslands, dominated by Panicum prionitis, and (8) trees. The proportion of area covered by each land-cover type within 200-m radius (we used range-finders to determine this distance) of each plot was estimated through direct field observations during each visit (i.e., 16 times). Beyond 200 meters, the presence of riparian forests interrupts the continuity of shrub swamps and marshes at many sites. We estimated only proportion of area and not actual area because we considered that this level of precision was sufficient for our objectives (i.e., is unlikely that small differences in the size of habitat patches are associated with changes in the presence and/or abundance of birds). Relative areas of each land-cover type were averaged among the 16 visits per site in data analysis.

\section{Data analyses}

We assessed the relative importance of alpha (i.e., species richness per plot) and beta diversity (i.e., compositional changes among plots) in shaping regional diversity (i.e., gamma diversity) through an additive model (i.e., gamma diversity $=$ alpha diversity + beta diversity; Lande 1996). In an additive framework, beta diversity represents the absolute magnitude of diversity "increment" or "excess" between a local scale and a regional scale (Chao et al. 2012). Thus, additive partitions of diversity decompose gamma diversity into alpha and beta components that can be compared because they are expressed in the same units (species richness in our study; Crist et al. 2003). We used R, version 3.2.0 (R Core Team 2015) and package vegan, version 2.3-0 (Oksanen 2011) for the calculation of diversity partition.

We calculated the total multiple-plot dissimilarity, derived from the pairwise Sørensen coefficient of dissimilarity, among the 60 plots (point count locations) along the fluvial system and, separately, among the 15 plots for each site. Sørensen coefficient is based on species occurrences and ranges from 0 to $1 ; 0$ indicates that assemblages are identical and 1 that they differ totally. Sørensen index was decomposed into components of species turnover (i.e., substitution of species between plots) and nestedness (i.e., elimination or addi- tion of species between plots; Baselga 2010). We used R (R Core Team 2015) and package betapart, version 1.3 (Baselga and Orme 2012) for the calculation of these dissimilarity índices.

We used variation-partitioning analysis (Borcard et al. 1992) performed by vegan packages (varpart function) in $R$ (R Core Team 2015). This allowed us to partition variation in assemblage composition (average of relative abundances among the 16 repeated surveys) per plot with respect to local environment variables (i.e., average of area proportion of each land cover among the 16 repeated surveys), spatial coordinates (i.e., position along the fluvial extension) and their combination. This analysis uses adjusted R-squared to control for number of variables in each set of predictors (PeresNeto et al. 2006) in redundancy analysis ordination (RDA). Significance of the overall RDA model and of individual fractions (i.e., effects of non-spatial environmental variables and spatial variables that are not shared by environmental variables) were evaluated by permutation tests. Prior to the analysis, relative abundances in bird composition data were transformed using Hellinger distance (Legendre and Legendre 1998). For the spatial matrix, we used a third-degree polynomial of the geographic coordinates, which allowed a representation of the geographic variation of species abundances by a cubic trend-surface of latitude and longitude (Legendre and Legendre 1998). This ensures the detection of more complex spatial features in the species data set than that provided by linear gradient patterns alone (Borcard et al. 1992).

We used nested (sites nested within upland ecoregions) permutational multivariate analysis of variance (PERMANOVA) to test for differences in composition per plot among sites (random and nested factor) and between upland ecoregions (main factor). Bray-Curtis index was used as dissimilarity measure of bird composition (i.e., average of relative abundances among the 16 repeated surveys) among plots. This analysis was performed through $\mathrm{R}$ (R Core Team 2015) using BiodiversityR package version 2.3-5 (Kindt and Coe 2005).

\section{Results}

A total of 12,738 records representing 162 bird species (Appendix) were recorded across the 60 plots and the 16 visits per plot. At each plot, we registered a mean \pm SE of $37.3 \pm$ 0.9 species (i.e., average per plot of the accumulated number of species across the 16 visits) and $212.3 \pm 14.2$ records (i.e., average per plot of the total number of records summed across the 16 visits). The most frequent species among 60 plots were Pitangus sulphurathus (recorded at $98 \%$ of plots), Jacana jacana (98\%), Paroaria capitata (93\%), Agelasticus cyanopus (88\%), Hymenops perspicillatus (87\%), Zonotrichia capensis (83\%), Furnarius rufus (80\%) and Vanellus chilensis (80\%).

Regional richness of the fluvial system (162 species) was shaped mainly by beta diversity among local assemblages (77\%; Fig. 2). Similar patterns, with gamma diversity shaped mainly by beta diversity (64-67\%), were found at each site (Fig. 2). 
Table 1. Decomposition of overall beta diversity (multiple-plot dissimilarities based on Sørensen index) in species turnover and nestedness components among the 15 plots at each site and among the 60 plots along the fluvial system.

\begin{tabular}{lccc}
\hline & $\begin{array}{c}\text { Overall beta diversity } \\
\text { (Sørensen index) }\end{array}$ & Species turnover & Nestedness \\
\hline Site A & 0.81 & 0.75 & 0.05 \\
Site B & 0.80 & 0.77 & 0.03 \\
Site C & 0.79 & 0.75 & 0.05 \\
Site D & 0.79 & 0.76 & 0.04 \\
Fluvial system & 0.94 & 0.93 & 0.01 \\
\hline
\end{tabular}

Plots along the fluvial system showed high overall beta diversity (Table 1). This overall beta diversity was mostly a result of high species turnover rather than nestedness among plots (Table 1). Patterns of beta diversity were similar at each site, with high species turnover among plots (Table 1).

Environmental and spatial matrices accounted for $30 \%$ of variation in bird composition along the fluvial system (RDA: adjusted-R $\left.\mathrm{R}^{2}=0.30 ; F=2.75 ; P=0.001\right)$. Total variation accounted for by the RDA model consisted of: (a) non-spatial environmental variation (11\%); (b) spatially-structured environmental variation (10\%); and (c) spatial variation of the species assemblages that was not shared by environmental variables (9\%; Fig. 3). Environmental matrix (i.e., environment alone and spatial structure of environmental variables) accounted for a higher proportion of variation in species composition (RDA: Adjusted R2 $=0.21 ; F=2.78 ; P=0.001$ ) than did spatial variables alone (RDA: adjusted $\mathrm{R}^{2}=0.09 ; F$ $=2.13 ; P=0.001)$.

Assemblage composition was different among sites (nested PERMANOVA: $P<0.001)$ but did not differ between upland ecoregions (nested PERMANOVA: $P=0.35$ ).

\section{Discussion}

The spatial heterogeneity within floodplain systems is often invoked to explain the high number of species present in fluvial environments (Ward et al. 1999, Naiman et al. 2005) but few studies have evaluated this relationship. Results of this study showed that bird species turnover is high, even at

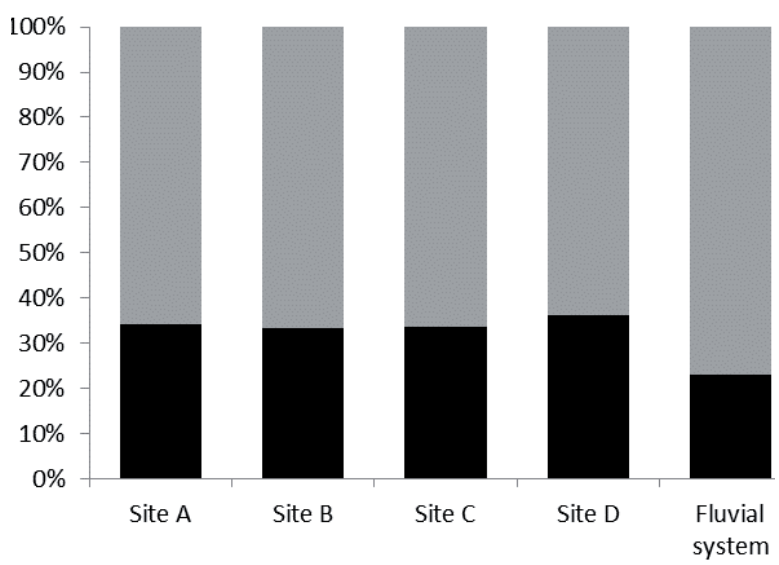

Figure 2. Decomposition of the regional richness (gamma diversity) of the fluvial system and of each site in alpha (black) and beta (gray) diversity components. a local scale, and that local environmental conditions (i.e., landscape composition) explained more of this pattern than did the location of the assemblages along the regional extension of the fluvial system. Nestedness dissimilarity was not as important as might have been expected if a latitudinal gradient in species richness (i.e., loss of species to the south) was present along the regional extension of the system. Thus, the regional bird richness of the river corridor was primarily influenced by species turnover within the system.

High productivity and environmental heterogeneity at local scales can make alpha diversity (i.e., species richness of individual plots) important in shaping regional diversity in fluvial systems (Ward et al. 1999, Naiman et al. 2005). In addition, because we sampled each plot 16 times during the course of two years, we likely were able to record all the species that might occur at each of the 60 plots, increasing species richness per plot which can, in turn, reduce turnover in species composition (White et al. 2010). However, results showed that beta diversity (i.e., changes of species composition among plots) was more important for shaping regional diversity in the Middle Paraná fluvial system. Similarly, other studies have shown a high spatial turnover of bird species in wetlands (e.g., Guadagnin et al. 2005, Ma et al. 2007).

For conservation purposes, the distinction between species turnover and nestedness is important because the two components of diversity require antithetic conservation strategies (Baselga 2010). Our results showed that differences in bird composition among plots were mainly due to species

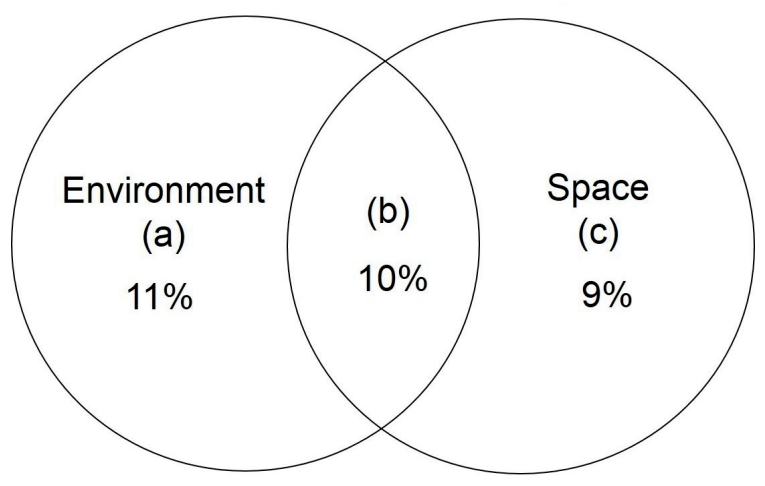

Figure 3. Variation-partitioning (expressed as percentage of variance explained) of the effects of non-spatial environmental conditions (a), spatially-structured environmental conditions (b) and spatial coordinates that was not shared by environmental conditions (c) on composition of bird assemblages along the regional extension of the Middle Paraná River, Argentina. 
turnover along the fluvial system. It indicates that conservation efforts should consider the Middle Paraná River as an integral unit because individual plots are poorly representative of the bird diversity of the region as a whole.

Local conditions accounted for an important proportion $(21 \%)$ of the changes in composition among plots. This could be attributed to niche-based community processes, with species differing in their ability to exist under different environmental conditions (Soininen et al. 2007). We used land-cover composition within plots as indicators of local conditions. It can be a good indicator of habitat availability for birds as different wetland species are associated with different land covers (Ronchi-Virgolini et al. 2008) and because individual species could select plots with specific landscape composition (e.g., Riffell et al. 2001).

Geographic position along extensive riparian corridors can reflect regional influences of both longitudinal (e.g., dispersion of organisms along the corridor) or lateral (dispersal from adjacent uplands) processes (Renöfält et al. 2005). Both processes shape the regional species pool in a given geographical position of the river corridor (e.g., sites in this study). Our study included a relatively large regional scale that covered a climatic gradient and in which sections of the fluvial system were surrounded by two different upland ecoregions. Moreover, spatial autocorrelation may help explain some of the variation in the composition of bird communities in this study because we used a nested design (i.e., the nearest plots within sites may be more similar to each other due to a higher probability of dispersal of species between them). These characteristics of the study area might suggest that the regional position of bird assemblages could be an important influence on spatial changes in bird composition. However, results showed that local conditions were more important in accounting for spatial changes in bird composition along the fluvial system.

Spatial position was, however, an important component of spatial changes in bird composition. Previous studies have shown that changes in composition of riparian biota can be predicted through regional classifications (e.g., ecoregions; Heino et al. 2002). Spatial position, however, did not reflect effects of lateral upland ecoregions on bird assemblages of the fluvial system (e.g., lateral input of species from surrounding upland habitats) because upland ecoregions were not an important influence on spatial changes in bird composition within the fluvial system. This result suggests that changes in the composition of bird assemblages of fluvial wetlands occur regardless of the upland ecoregion adjacent to the riparian system. Bird assemblage composition was, nevertheless, different among the four sites along the fluvial system, indicating the importance of regional context (e.g., influence of the species pool) on spatial variation in species composition of local assemblages.

Bird studies in riparian corridors have shown that local conditions (e.g., Godinho et al. 2010, Henden et al. 2013) and dispersal processes (Da Silva 1996, Nores et al. 2005) are important influences on spatial variation in assemblage composition. Studies that simultaneously consider the influ- ence of local conditions and spatial position on bird communities along regional extensions of fluvial systems are rare (e.g., Miller et al. 2004, Godinho et al. 2010), yet represent an important step in understanding the relative influences of local- versus regional-scale variables on riparian assemblages. Our findings were similar to those of Miller et al. (2004) and Godinho et al. (2010), who reported that local conditions were important influences on spatial changes in bird assemblages along riparian forests.

A high proportion of spatial variation in assemblage composition was not accounted for by landscape composition and/or spatial variables. Unaccounted variation likely reflects local effects of unmeasured (biotic or abiotic) environmental variables, spatial structures that have been missed because they require more complex functions to be described, to the fact that some species do not occupy all patches of suitable habitat ('unsaturation') and to stochastic fluctuations of the communities, such as chance colonization, random extinction and ecological drift (random changes in relative abundance of species; Borcard et al. 1992, Titeux et al. 2004, Chase and Myers 2011). Nevertheless, it is not uncommon to observe a low percentage of explained variation in ecological studies, because species' abundance data often are very noisy (Titeux et al. 2004, Godinho et al. 2010).

The widespread loss and degradation of floodplain habitats are pressing concerns in the conservation of avian diversity (Brawn et al. 2001). Proper conservation and management of ecosystems requires that we understand the processes by which beta diversity is created and maintained (Legendre et al. 2005). In this study, we showed that environmental heterogeneity created by the flood pulses along the fluvial system is an important factor to sustain bird regional diversity of the fluvial system through effects on beta diversity.

Acknowledgements. We thank the many assistants who helped during field surveys. This study received financial support of Consejo Nacional de Investigaciones Científicas y Técnicas (PIP N ${ }^{\circ}$ 0463) and Francois Vuilleumier Fund 2008 (Neotropical Ornithological Society). We are grateful to J. Blake, M. Quiroga and I. Martinez for English editing and their constructive comments on the drafts of this paper.

\section{References}

Amori, G., S. Gippoliti, L. Luiselli and C. Battisti. 2010. Are there latitudinal gradients in taxa turnover? A worldwide study with Sciuridae (Mammalia: Rodentia). Community Ecol. 11: 22-26.

Baselga, A. 2010. Partitioning the turnover and nestedness components of beta diversity. Global Ecol. Biogeogr. 19: 134-143.

Baselga A. and C.D. Orme. 2012. Betapart: an R package for the study of beta diversity. Methods Ecol. Evol. 3: 808-812

Belmaker, J. and W. Jetz. 2012. Regional pools and environmenta controls of Vertebrate richness. Am. Nat. 179: 512-523.

Borcard, D., P. Legendre and P. Drapeau. 1992. Partialling out the spatial component of ecological variation. Ecology 73: 10451055. 
Brawn, J.D., S.K. Robinson and F.R. Thompson III. 2001. The role of disturbance in the ecology and conservation of birds. Annu. Rev. Ecol. Syst. 32: 251-276.

Cabrera A.L. 1994. Regiones fitogeográficas argentinas. ACME, Buenos Aires.

Cáceres, L.M. 1980. Caracterización climática de la Provincia de Santa Fe. Ministerio de Agricultura y Ganadería, Santa Fe.

Chao, A., C. Chiu and T.C. Hsieh. 2012. Proposing a resolution to debates on diversity partitioning. Ecology 93: 2037-2051.

Chase, J.M. and J.A. Myers. 2011. Disentangling the importance of ecological niches from stochastic processes across scales. Philos. Trans. R. Soc. B 366: 2351-2363.

Crist, T.O., J.A. Veech, J.C. Gering and K.S. Summerville. 2003. Partitioning species diversity across landscapes and regions: a hierarchical analysis of $\alpha, \beta$ and $\gamma$ diversity. Am. Nat. 162: 734743.

Da Silva, J.M. 1996. Distribution of Amazonian and Atlantic birds in gallery forests of the Cerrado Region, South America. Ornitol. Neotrop. 7: 1-18.

Demars, B.O.L. and D.M. Harper. 2005. Distribution of aquatic vascular plants in lowland rivers: separating the effects of local environmental conditions, longitudinal connectivity and river basin isolation. Freshwater Biol. 50: 418-437.

Dobkin, D.S. and Rich, A.C. 1998. Comparison of line-transect, spot map, and point-count surveys for birds in riparian habitats of the Great Basin. J. Field Ornithol. 69: 430-443.

Godinho, C., J. Rabaça and P. Segurado. 2010. Breeding bird assemblages in riparian galleries of the Guadiana River basin (Portugal): the effect of spatial structure and habitat variables. Ecol. Res. 25: 283-294.

Gregory, R.D., D.W. Gibbons and P.F. Donald. 2004. Bird census and survey techniques. In W.J. Sutherland, I. Newton and R.E. Green (eds.), Bird Ecology and Conservation: A Handbook of Techniques. Oxford University Press, Oxford. pp. 17-39.

Gu, W. and R.K. Swihart. 2004. Absent or undetected? Effects of non-detection of species occurrence on wildlife-habitat models. Biol. Conserv. 116: 195-203.

Guadagnin, D.L., A.S. Peter, L.F. Carvalho-Perello and L. Maltchik. 2005. Spatial and temporal patterns of waterbird assemblages in fragmented wetlands of Southern Brazil. Waterbirds 28: 261404.

Heino, J., T. Muotka, R. Paavola, H. Hämäläinen and E. Koskenniemi. 2002. Correspondence between regional delineations and spatial patterns in macroinvertebrate assemblages of boreal headwater streams. J. North Am. Benthological Soc. 21: 397-413.

Henden J-A., N.G. Yoccoz, R.A. Ims and K. Langeland. 2013. How spatial variation in areal extent and configuration of labile vegetation states affect the riparian bird community in Arctic Tundra. PLOS ONE 8:63312

Iriondo, M.H., J.C. Paggi and M.J. Parma. 2007. The Middle Paraná River: limnology of a subtropical wetland. Springer-Verlag, Berlin.

Kilpatrick, A.M., W.A. Mitchell, W.P. Porter and D.J. Currie. 2006. Testing a mechanistic explanation for the latitudinal gradient in mammalian species richness across North America. Evol. Ecol. Res. 8: 333-344.

Kindt, R. and R. Coe. 2005. Tree diversity analysis. A manual and software for common statistical methods for ecological and biodiversity studies. World Agroforestry Centre (ICRAF), Nairobi. ISBN 92-9059-179-X.

Lande, R. 1996. Statistics and partitioning of species diversity, and similarity among multiple communities. Oikos 76: 5-13.
Legendre, P., D. Borcard and P.R. Peres-Neto. 2005. Analyzing beta diversity: partitioning the spatial variation of community composition data. Ecol. Monogr. 75: 435-450.

Legendre, P. and L. Legendre. 1998. Numerical Ecology. Elsevier, Amsterdam

Lessard, J-P., M.K. Borregaard, J.A. Fordyce, C. Rahbek, M.D. Weiser, R.R. Dunn and N.J. Sanders. 2011. Strong influence of regional species pools on continent-wide structuring of local communities. Proc. R. Soc. B 279: 266-274.

Ma, Z., X. Gan, C. Choi, K. Jing, S. Tang, B. Li and J. Chen. 2007. Wintering bird communities in newly-formed wetland in the Yangtze River estuary. Ecol. Res. 22: 115-124.

Miller, J.R., M.D. Dixon and M.G. Turner. 2004. Response of avian communities in large-river floodplains to environmental variation at multiple scales. Ecol. Appl. 1394-1410.

Naiman, R.J., H. Décamps and M.E. McClain. 2005. Riparia: Ecology, Conservation and Management of Streamside Communities. Elsevier/Academic Press, San Diego.

Nestler, J.M., C.R.M. Baigún, N. Oldani and L.J. Weber. 2007. Contrasting the Middle Paraná and Mississippi Rivers to develop a template for restoring large floodplain river ecosystems. Int. J. River Basin Management 5: 305-319.

Nores, M, M.M. Cerana and D.A. Serra. 2005. Dispersal of forest birds and trees along the Uruguay River in southern South America. Divers. Distrib. 11: 205-217.

Oksanen, J. 2011. Multivariate Analysis of Ecological Communities in R: vegan tutorial. URL: http://cran.r-project.org.

Olson, D.M., E. Dinerstein, E.D. Wikramanayake, N.D. Burgess, G.V.N. Powell, E.C. Underwood, J.A. D'Amico, I. Itoua, H.E. Strand, J.C. Morrison, C.J. Loucks, T.F. Allnut, T.H. Ricketts, Y. Kura, J.F. Lamoreux, W.W. Wettengel, P. Hedao and K.R. Kassem. 2001. Terrestrial ecoregions of the world: a new map of life on Earth. BioScience 51: 933-938.

Peres-Neto, P.R., Legendre, P., Dray, S. and D. Borcard. 2006. Variation partitioning of species data matrices: estimation and comparison of fractions. Ecology 87: 2614-2625.

Perry, R.W., T.B. Wigley, M.A. Melchiors, R.E. Thill, P.A. Tappe and D.A. Miller. 2011. Width of riparian buffer and structure of adjacent plantations influence occupancy of conservation priority birds. Biodivers. Conserv. 20: 625-642.

R Core Team. 2015. R: A Language and Environment for Statistical Computing Version 3.2.0. $\mathrm{R}$ Foundation for Statistical Computing, Vienna. Available at: http://www.r-project.org.

Ralph, C. J., G. R. Geupel, P. Pyle, T. E. Martin, and D. F. DeSante. 1993. Handbook of field methods for monitoring landbirds. General Technical Report PSW-GTR-149. Pacific Southwest Research Station, Albany, California, USA.

Remsen, J.V.J., C.D. Cadena, A. Jaramillo, M. Nores, J.F. Pacheco, M.B. Robbins, T.S. Schulenberg, F.G. Stiles, D.F. Stotz and K.J. Zimmer. 2015. A classification of the bird species of South America. American Ornithologists' Union. Available at: http:// www.museum.lsu.edu/ Remsen/SACCBaseline.htm.

Renöfält, B.M., C. Nilsson and R. Jansson. 2005. Spatial and temporal patterns of species richness in a riparian landscape. $J$. Biogeogr. 32: 2025-2037.

Ricklefs, R.E. 1987. Community diversity: relative roles of local and regional processes. Science 235: 168-171.

Riffell, S.K., B.E. Keas and T.M. Burton. 2001. Area and habitat relationships of birds in great lakes coastal wet meadows. Wetlands 21: 492-507.

Robbins, C.S. 1981. Effect of time of day on bird activity. Stud. Avian Biol. 6: 275-286. 
Rojas, A. and J.H. Saluso. 1987. Informe Climático de la Provincia de Entre Ríos. Instituto Nacional de Tecnología Agropecuaria, Paraná.

Ronchi-Virgolini, A.L., A.H. Beltzer and A. Manzano. 2008. Bird communities in wetlands along the Lower Paraná River, Entre Ríos, Argentina. Avian Biol. Res. 1: 153-163.

Sabattini, R.A. and V.H. Lallana. 2007. Aquatic macrophytes. In M.H. Iriondo, J.C. Paggi and M.J. Parma (eds.), The Middle Paraná River: Limnology of a Subtropical Wetland. SpringerVerlag, Berlin. pp. 341-362.

Savard, J.-P. L. and Hooper, T. D. 1995. Influence of survey length and radius size on grassland bird surveys by point counts at Williams Lake, British Columbia. In: Ralph, C. J., Sauer, J. R. and Droege, S. (eds), Monitoring Bird Populations by Point Counts. Gen. Tech. Rep. PSW-GTR- 149. Pacifie Southwest Research Station, Forest Service, U. S. Department of Agriculture, Albany, CA pp. 57-62.

Soininen, J., R. McDonald and H. Hillebrand. 2007. The distance decay of similarity in ecological communities. Ecography 30: $3-12$.

Sullivan, S.M.P., M.C. Watzin and W.S. Keeton. 2007. A riverscape perspective on habitat associations among riverine bird assemblages in the Lake Champlain Basin, USA. Landsc. Ecol. 22: 1169-1186.

Titeux, N., M. Dufrene, J-P. Jacob, M. Paquay and P. Defourny. 2004. Multivariate analysis of a fine-scale breeding bird atlas using a geographical information system and partial canonical correspondence analysis: environmental and spatial effects. $J$. Biogeogr. 31: 1841-1856.
Tockner, K., M.S. Lorang and J.A. Stanford. 2010. River flood plains are model ecosystems to test general hydrogeomorphic and ecological concepts. River Res. Appl. 26: 76-86.

Verner, J. and K.A. Milne. 1989. Coping with sources of variability when monitoring population trends. Ann. Zool. Fenn. 26: 191-199.

Ward, J.V., K. Tockner and F. Schiemer. 1999. Biodiversity of floodplain river ecosystems: ecotones and connectivity. Regul. Rivers: Res. Mgmt. 15: 125-139.

White, E.P. and A.H. Hurlbert. 2010. The combined influence of the local environmental and regional enrichment on bird species richness. Am. Nat. 175: 35-43.

White, E.P., S.K. Ernest, P.B. Adler, A.H. Hurlbert and S.K. Lyons. 2010. Integrating spatial and temporal approaches to understanding species richness. Phil. Trans. R. Soc. B 365: 3633-3643.

Whittaker, R.H. 1960. Vegetation of the Siskiyou Mountains, Oregon and California. Ecol. Monogr. 30: 279-338.

Received July 1, 2015

Revised December 10, 2015, February 6, 2016 Accepted March 2, 2016

\section{Appendix}

List of birds registered in shrub swamps and marshes along the Middle Paraná River.

The file may be downloaded from www.akademiai.com 